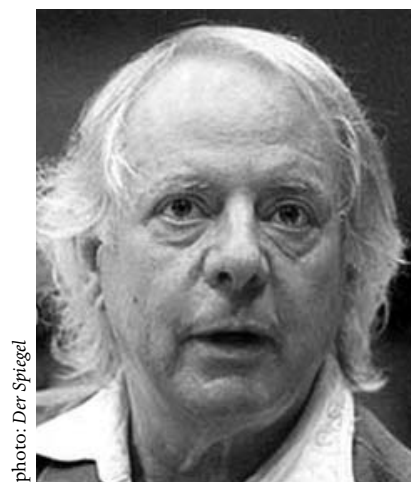

\title{
BECOMING THE SYNTHI-FOU: STOCKHAUSEN AND THE NEW KEYBOARDISM
}

\author{
Michael Fowler
}

Karlheinz Stockhausen embraced the potential of electronic music to generate new timbres and acoustic typologies early in his career. After first experimenting with magnetic tape in works such as Gesang der Jünglinge (1955) and Kontakte (1958-60), he later embraced other synthesis technologies for the production of large-scale spatial electro-acoustic works such as Sirius (1970) and Oktophonie (1990-91). ${ }^{1}$ His interest in technological advances in sound design and sound diffusion also managed to penetrate his highly evolved Klavierstücke.

By the completion of Klavierstück XIV in 1984, Stockhausen had achieved a formidable depth in the series. As a group of piano pieces, they represent a continuum of compositional investigations. At the boundaries lie the polyvalency of Klavierstück XI and the total serialism of Klavierstïcke I-IV. Similarly, the technical demands explored throughout the series are just as diverse - from the rapid attacks of grace-note constellations in Klavierstücke V \& VI, to clusters and chord glissandi in Klavierstück $X$, and theatrical gestures and vocalization in Klavierstücke XII, XIII and XIV. Though the complex mechanism of the piano remains unchanged since the turn of the 20th century, in the 32 years intervening between Klavierstück I and Klavierstück XIV, electronic instrument design and manufacture progressed significantly. ${ }^{2}$ By 1984 the modernday synthesizer had been in use for over a decade within popular music, and the availability of portable instruments with editing and programming capabilities was commonplace. Though long-time Stockhausen collaborators Harald Bojé and Peter Eötvös realized works such as Pole für 2 (1969-70) and Spiral (1968) with early electronic instruments, it was not until the 1981 staging of Stockhausen's first opera Donnerstag aus Licht (1978-80) that the modern synthesizer began its prominence in the composer's oeuvre, eventually finding its way into the Klavierstücke.

Seven years after the completion of Klavierstück XIV, and following his precedent of developing solo piano works from keyboard-focused scenes from the Licht cycle (as with Klavierstücke XII, XIII \& XIV), Stockhausen's opera, Dienstag aus Licht, became the surrogate to arguably his most ambitious solo keyboard work of the series, Klavierstück $X V$ (Synthi-Fou). In contrast to the hype, detailed analyses and discussions that have arisen from Stockhausen's early solo piano music, ${ }^{3}$ the pivotal Klavierstück $X V$ has been notably neglected. The work represents one of the most significant manifestations of Stockhausen's ideas about the connexion between technology and the art of performance, and in

\footnotetext{
${ }^{1}$ For a detailed discussion of Stockhausen's use of MIDI synthesizers in Oktophonie see Clarke and Manning (2008).

2 See Chadabe (1997).

${ }^{3}$ e.g. see Henck (1980), Toop (1991), Lewin (1993), Truelove (1984) et al.
} 
particular, the future of keyboard music and its practitioners. Its neglect by performers may be a function of the technological demands: at least four synthesizers with octophonic tape projection, or the requirement for the interpreter to compose over 131 timbres and synchronize with 8channels of audio. Stockhausen gives an insight into his ideas about the evolution of keyboard music in his lecture Clavier Music 1992:

Today I see the development this way: piano music has come to an end and something quite different is coming. I sense it clearly: with the claviers made up to this time, there is nothing new to discover any more. ${ }^{4}$

Indeed, Klavierstück $X V$ is a new type of keyboard music, at least for any pianist familiar with the early Klavierstücke. Its connection to the second act of Dienstag aus Licht is significant, and holds an important narrative that must be revealed by the interpreter in order to achieve Stockhausen's conceptual goals for the work. As a last dramatic flourish, Jenseits, the final section of Dienstag, introduces a technology-obsessed being, a Fou, ${ }^{5}$ who mischievously, and with great humour, wit and élan, enacts a joyful keyboard solo that manages to transfix an onstage choir in the middle of plans for war. During the solo, 8 loudspeakers fill the auditorium with the electronic work Oktophonie. At times the sounds of the tape and keyboards collide, conjoin and explode in all directions. The Synthi-Fou's final gesture is to count backwards from 13 synchronously with the electronic music. In doing so he removes 10 long fingers, his ears and nose, gives a charming bow, and then mischievously stalks off stage.

Dienstag is Stockhausen's war opera, with two main protagonists, Lucifer and Michael, engaged in a musical and ideological battle. Indeed, conflict is used as a dramatic device for the larger part of the work, until the appearance of the Synthi-Fou at the close of the opera. The Synthi-Fou thus represents a supernatural yet reconciliatory figure whose fantastic, 'fouturistic,' surreal and cosmic keyboard timbres are both spellbinding and transformational. His command of technology and synthesizers is virtuosic: he is an absolute representation of Stockhausen's vision for the future of keyboard playing.

Without the extravagance of an opera stage or set, the dislocation of the final part of Dienstag into the solo Klavierstück XV does remove certain continuities in terms of a narrative context and dramatic foil. But, in spite of the difficulties of presenting the work as a piece of theatre embodied through a Klavierstück, the overwhelming issues for the interpretation of Klavierstück XV reside in the new performance practices required of the keyboardist. Stockhausen clearly understood the potential for the synthesizer's control surfaces to enact new types of virtuosity:

Synthesizer playing has 'arrived,' it's already evident ... A new generation is coming, which once again plays keyboard instruments. But the keys mean something radically different than they did at the beginning of my education. Synthesizers and samplers are no longer dependent on finger dexterity ... The force of striking a key doesn't any longer necessarily have anything to do with loudness, but instead can - according to the programming - bring about timbre alterations, or degrees of amplitude and frequency modulation; or a note may begin at some point to vibrate more or less rapidly, responding to the key pressure ... ${ }^{6}$

${ }^{4}$ Stockhausen (1993).

5 From the French word for crazed. (Robin Maconie adds: also from the indecent verb 'foutre'. Stockhausen's character is saying ' $f$... you' to the audience in the spirit of the farting trum pet in Trans and the flutist's 'Salve Satanelli!' in Samstag. - Ed.)

${ }^{6}$ Stockhausen (1993). 
Within Synthi-Fou lie myriad examples of passages in which the technology and capabilities of a modern synthesizer are required to realize the notation.?

Figure 1 is typical of the programming complexities inherent in the work.

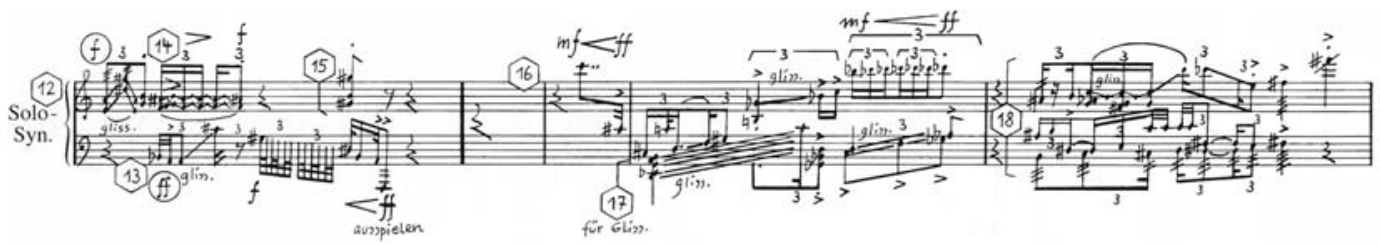

Figure 1:

Klavierstück XV, Synthi-Fou m.10-14. (C) Stockhausen Foundation for Music, Kürten, Germany (www.stockhausen.org).
In the example, automation and triggering are necessary to overcome three basic problems. The most obvious involves glissandi; not only of single notes, but also of chords. The second involves the selective assigning of amplitude modulation, or vibrato (marked with angular lines; the more lines the more vibrato), while the final problem involves microtonal tunings. In the left-hand passage of the first bar, beat 3 involves a 'chromatic' scale passage. The passage begins on G\# and ends on D\# (a perfect 4th), though the number of notes used to traverse this distance is 12 ! To properly realize this passage, a microtonal tuning has to be employed, and the scale physically played out through 12 keys, though only through 400 cents. The relationship between the notation and where it becomes realized on the instrument is also a peculiarity of the performance practice involved in Klavierstück XV. Due to the necessity in delineating zones tagged with certain automations, different octaves on the keyboard are employed, while still remaining accurate to the relative registers notated in the score. The modern synthesizer has the ability to relinquish its traditional geography and become a utility in which the player overlays specific manipulations of register across the keyboard.

Other triggering in Synthi-Fou occurs when rapid chord glissandi are notated. In Figure 2 the left hand on beat 4 requires a quintuplet accented chord scale to bend upward in varying degrees of pitch (i.e. upper voice of chord; ostensibly from $\mathrm{D} b-\mathrm{E}-\mathrm{G}-\mathrm{A}-\mathrm{C} \#$ ). The tempo, style of notation, and capabilities of a modern synthesizer indicate that the lower notes of the chords be triggered via their upmost voice. Figure 2 similarly demonstrates the improvisation windows of the work (empty boxes with rhythmic duration marked), and points where Stockhausen nominates timbre changes (marked as numbers within hexagons). In addition to these numerous programming demands, the interpreter of Synthi-Fou must also compose (synthesize) 131 numbered timbres. Added to these sounds are the 37 improvisational boxes in which thematic materials and timbres are freely chosen. Stockhausen expected the virtuosity displayed in Klavierstück XV to be particularly evident through the originality of these sections. Here, the interpreter is free to conjure bizarre sound effects, samples, Klang-Bombe, and spatial trajectories that tastefully, but with some humour, compliment the electronic music of Oktophonie.

\footnotetext{
7 Robin Maconie also notes that the 'Synthi' in Synthi-Fou is a reference to the earlier analogue instrument, the Synthi 100 made by EMS, for which Stockhausen composed Sirius (1977). Maconie implies that Klavierstücke XV was considered by Stockhausen as a challenge to the younger digital generation to test the usability, malleability and operational con straints of the modern synthesizer in light of the capabilities of the Synthi 100.
} 


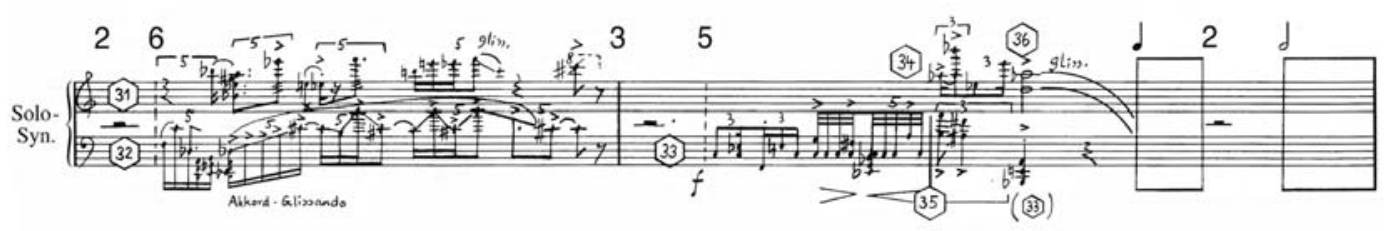

Figure 2:

Klavierstück XV, Synthi-Fou m.2627. (C) Stockhausen Foundation for Music, Kürten, Germany (www.stockhausen.org).
Stockhausen's new role for the keyboard performer in Klavierstück $X V$ arose in a manner he was intimately accustomed to: through collaboration. For Synthi-Fou this collaboration came with his son Simon Stockhausen, the dedicatee and first interpreter of the work. The influence of Simon Stockhausen's reputation as a synthesizer virtuoso is readily apparent within the piece. Simon's performances of the work came to embody an innate understanding of musical control via new human-machine interfaces. To fully embrace the concept of the work, the performer must use all manner of control surfaces available within the technology - slide ribbons, faders, aftertouch, pitch and modulation wheels, foot pedals and switches. Similarly, Stockhausen wanted the piece to be performed with at least four keyboards to create a new virtuosic choreography and facilitate the use of an expanded timbre palette. But the requirement for a large library of timbres to be composed by the performer creates a situation for Stockhausen in which the notated score of Klavierstück XV does not account for the actual sounds of the work (merely the pitches). He anticipates such difficulties through a documentation process that is extensive. Stockhausen provides an 'acoustical supplement' in addition to a list of the actual instruments used by Simon in the première, and a verbal description of the timbres. The supplement is a CD of Simon Stockhausen naming and demonstrating each of the 131 sounds on the instruments he used. This supplement is used as a guide for future interpreters to model (or even sample) their sounds. There is perhaps only an historical interest for the naming of the instruments used by Simon in the premiere, but undoubtedly Stockhausen understood that as technology progresses, new instruments emerge. Because of this, Klavierstück $X V$ is not tied to a particular type of synthesizer(s), nor is there any real call for authenticity by using Simon's instruments. The interpreter ultimately makes decisions about which instruments to use in regard to its programming potential, its range of timbres, and the wealth of its control surfaces.

Consequently, the technical knowledge required to produce a version of Klavierstück XV goes far beyond any of the previous Klavierstücke. Essentially, Stockhausen asks the traditionally-minded pianist to learn, and become an expert, on a new instrument and a new technology. The transformation from pianist to synthesizer player (to becoming the Synthi-Fou) involves developing a completely new knowledge base. The level of mastery of the instrument becomes audible in the originality and textural detail of an interpreter's sounds, and the degree to which these can be controlled and manipulated using new types of interfaces. Added to these issues are the practical problems of dealing with large sound banks on multiple instruments. Consequently, creating a version of the work also includes designing a method to address and scroll these banks through a master control to enable stop/start rehearsal (see Figure 3 for an example of the author's system). Similarly, controlling the amplitude envelopes of myriad sound banks through touch sensitivity and numerous volume pedals requires new performance practice skills, unknown to traditional pianists. 


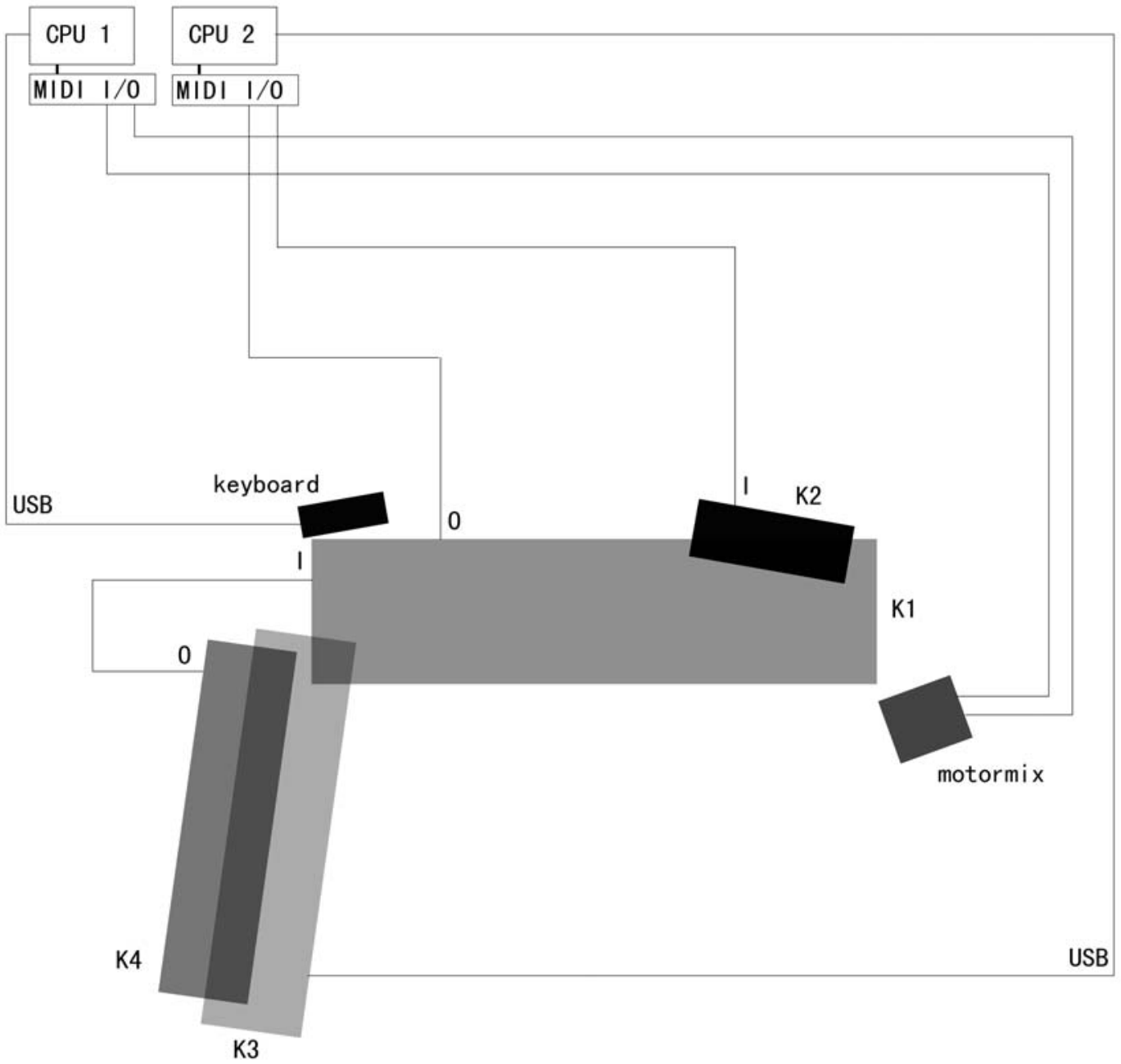

Figure 3:

Typical control schema for Klavierstück XV. Two computers are used (CPU 1\&2) for sound generation and clocking. CPU 1 runs sampling/trigger software whose interface is a computer keyboard. Additionally, CPU 1 runs sound synthesis software whose interface is an 8 -fader midi control interface. K1 and $\mathrm{K} 2$ are keyboard synthesizers, and the $\mathrm{K} 3$ and $\mathrm{K} 4$ midi keyboard controllers. K4 triggers sounds on $\mathrm{K} 1$, and $\mathrm{K} 3$ is the interface for a software synthesizer located on CPU 2. A master clocking software is run on CPU 2 to synchronize program change messages from $\mathrm{K} 1$ to $\mathrm{K} 2$ and $\mathrm{K} 3$.
New methods for control are similarly required in mastering the useful effect of aftertouch - a fundamental control parameter of the modern synthesizer. After a key is struck, any number of delayed attacks, vibrato, glissandi, or other automated envelope functions can be precisely activated and manipulated according to the amount of pressure executed on the key. The performer's agility in differentiating different pressure-levels for aftertouch control remains one of the most difficult technical demands of the synthesizer. The first measure of Figure 2 shows a typical passage in Klavierstück XV where aftertouch is one option that can be employed to overcome different automations occurring on the same note. Because the left hand requires a $\mathrm{C \#}$ be played twice with different automations (first time a glissando down to B, second time a glissando up to D), degrees of aftertouch can be utilized to distinguish between these automations. Yet other types of control can be applied through key velocity. By programming for the speed at which the key is struck, a corresponding envelope can be triggered to control the relative speed of the glissandi, or its range and amplitude, or the degree or type of accent to be used.

Stockhausen's detailed notation and knowledge of the programming potentials of the modern synthesizer delineate Klavierstück $X V$ in a very particular manner. Even though the following work of the 
series, Klavierstück XVI, includes the option of a traditional 'stringed' keyboard plus synthesizer(s), Klavierstück XVII (Komet), Klavierstück XVIII (Mittwochs-Formel) and the yet to be premièred Klavierstück XIX (Sonntags-Abschied) each adhere to the precedent of using the synthesizer as the primary keyboard. Each is also extracted from Licht scenes, and for Klavierstück XVI and Klavierstück XVII (Komet), involve the use of a multi-channel electronic tape part from Freitag aus Licht. The inclusion of traditional 'stringed' piano in Klavierstück XVI undoubtedly arose after the 1997 Micheli Piano Competition commissioned Stockhausen for a new work for the finalists. A performance version of the score was prepared by Antonio Pérez Abellán and premièred in 1999.

Following on from the use of improvisation boxes in Klavierstück XV, the score of Klavierstück XVI is comprised of a detailed notation of the 12-channel electronic music (the 12th sound-scene of Freitag) with the instructions that:

one plays and/or sings, whistles, plucks etc. any number of pitches synchronous with the tape. The pitches (individual notes, individual intervals and single chords - no melodic groups) should only occasionally be played in the register notated ...

(See Figure 4).

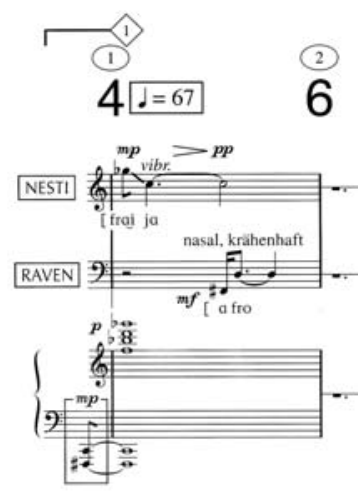

Figure 4:

Klavierstück XVI, m.1-5. C Stockhausen Foundation for Music, Kürten, Germany (www.stockhausen.org)

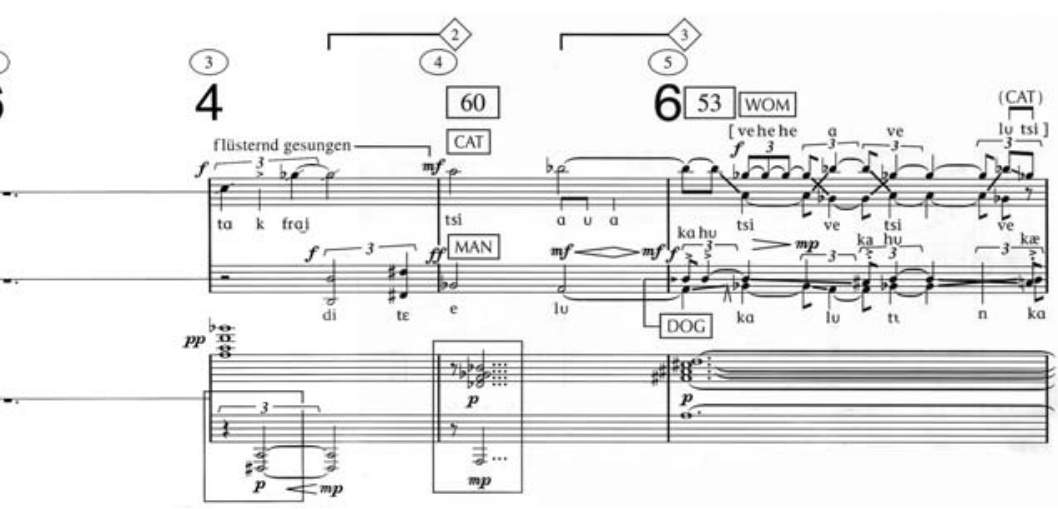

The instrumentation for the work lists both stringed piano and electronic keyboard instruments ad lib. In the mid 1990s, Pérez Abellán had become Stockhausen's primary synthesizer collaborator, participating not only in world première performances, but also preparing timbres for the electronic music of the last operas of Licht. Similarly, the final Klavierstücke (XVI-XIX) were a result of the close collaborative relationship between Stockhausen and Pérez Abellán, and in particular, Abellán's command of synthesizer programming and synthesizer performance practices. This relationship becomes evident in the types of 'freedom' that proliferate in Klavierstück XVI and Klavierstück XVII (Komet). In the latter, a similar system of improvisation staves occurs in which only suggested pitches are notated, accompanied by a detailed notation of the 4-channel electronic music. As with Klavierstück XVI, the score of Klavierstück XVII (Komet) is published with Pérez Abellán's version of the work (both in print and on Stockhausen-Verlag CD). The close relationship between performer and composer meant that the selection of timbres, and the generation and synchronization of the synthesizer with the electronic music, could be studiously overseen by Stockhausen. Moreover, Stockhausen had built a trust in the abilities of Pérez Abellán to craft interpretations of originality and wit, and build timbres appropriate to the aesthetics of Licht. The composer was also keen to promote and legitimize synthesizer performance, and saw an 
important position in the collaborative role that had been firstly established by his son Simon.

By the late 1990s Stockhausen managed to elevate the synthesizer to an important status in his music. Using it as both a compositional utility and virtuoso platform, he prepared timbres and sequences for electronic music, and wrote important solo and ensemble roles within Licht. Stockhausen managed to fulfil his ideas about the evolution of keyboard playing by utilizing the instrument for its inherent capabilities to manipulate and spatialize sound through new human-machine interfaces. Similarly, by seeking out intensive collaborative partnerships he found suitable performers to champion the instrument. Because of these intense collaborations he could investigate and implement the technology of the instrument, discovering the most idiomatic means to which it could be used in live performance. These investigations become forcefully embodied in Klavierstück XV, a work that certainly represents the arrival of the synthesizer as a serious concert instrument. By making a definitive break in instrumentation from his previous Klavierstücke, Stockhausen accentuates this juncture, in effect calling for a paradigm shift in keyboard performance through the embracing of new digital technologies. These technologies subsequently demand new approaches to the act of preparing and playing a score, and are far removed from traditional keyboard practise. For Stockhausen, the appearance of the Synthi-Fou was inevitable, a necessity for renewal in the Klavierstücke, and a cause célèbre for a revived future of keyboard performance, for new instruments, and for new timbres.

\section{BIBLIOGRAPHY}

Joel Chadabe, 1997. Electric Sound: The Past and Promise of Electronic Music. (Upper Saddle River, New Jersey: Prentice Hall).

Michael Clarke and Peter Manning, 2008. 'The influence of technology on the composition of Stockhausen's "Oktophonie," with particular reference to the issues of spatialisation in a threedimensional listening environment' in Organised Sound (13/3), pp.177-187.

Herbert Henck, 1980. Karlheinz Stockhausen's Klavierstück X: A Contribution toward Understanding Serial Technique: History, Theory, Analysis, Practice, Documentation. Deborah Richards (ed.) (Cologne: Neuland Musikverlag Herbert Henck).

Jerome Kohl, 1993. 'Time and Light' in Contemporary Music Review (7/2), pp.203-219.

David Lewin, 1993. Musical Form and Transformation: Four Analytic Essays (New Haven: Yale University Press).

Robin Maconie, 2005. Other planets: the music of Karlheinz Stockhausen (Lanham, MD: Scarecrow Press).

Karlheinz Stockhausen, 1993. 'Clavier Music 1992' in Perspectives of New Music (31/2), pp.136-49.

Richard Toop, 1991. 'Last Sketches of Eternity: The First Versions of Stockhausen's Klavierstück VI’ in Musicology Australia (14), pp.2-24.

Stephen Truelove, 1998. 'The Translation of Rhythm into Pitch in Stockhausen's Klavierstück XI’ in Perspectives of New Music (36/1), pp.189-220. 